\title{
Mental health service preferences of patients and providers: a scoping review of conjoint analysis and discrete choice experiments from global public health literature over the last 20 years (1999-2019)
}

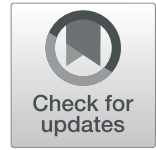

Anna Larsen ${ }^{1}$, Albert Tele ${ }^{2}$ and Manasi Kumar ${ }^{3^{*}}$

\begin{abstract}
Background: In designing, adapting, and integrating mental health interventions, it is pertinent to understand patients' needs and their own perceptions and values in receiving care. Conjoint analysis (CA) and discrete choice experiments (DCEs) are survey-based preference-elicitation approaches that, when applied to healthcare settings, offer opportunities to quantify and rank the healthcare-related choices of patients, providers, and other stakeholders. However, a knowledge gap exists in characterizing the extent to which DCEs/CA have been used in designing mental health services for patients and providers.

Methods: We performed a scoping review from the past 20 years (2009-2019) to identify and describe applications of conjoint analysis and discrete choice experiments. We searched the following electronic databases: Pubmed, CINAHL, PsychInfo, Embase, Cochrane, and Web of Science to identify stakehold,er preferences for mental health services using Mesh terms. Studies were categorized according to pertaining to patients, providers and parents or caregivers.

Results: Among the 30 studies we reviewed, most were published after 2010 (24/30, 80\%), the majority were conducted in the United States $(11 / 30,37 \%)$ or Canada (10/30, 33\%), and all were conducted in high-income settings. Studies more frequently elicited preferences from patients or potential patients $(21 / 30,70 \%)$ as opposed to providers. About half of the studies used CA while the others utilized DCEs. Nearly half of the studies sought preferences for mental health services in general $(14 / 30,47 \%)$ while a quarter specifically evaluated preferences for unipolar depression services (8/30,27\%). Most of the studies sought stakeholder preferences for attributes of mental health care and treatment services (17/30, 57\%).
\end{abstract}

\footnotetext{
* Correspondence: manni_3in@hotmail.com

${ }^{3}$ Department of Psychiatry, University of Nairobi, (47074), Nairobi 00100,

Kenya

Full list of author information is available at the end of the article
}

(c) The Author(s). 2021 Open Access This article is licensed under a Creative Commons Attribution 4.0 International License, which permits use, sharing, adaptation, distribution and reproduction in any medium or format, as long as you give appropriate credit to the original author(s) and the source, provide a link to the Creative Commons licence, and indicate if changes were made. The images or other third party material in this article are included in the article's Creative Commons licence, unless indicated otherwise in a credit line to the material. If material is not included in the article's Creative Commons licence and your intended use is not permitted by statutory regulation or exceeds the permitted use, you will need to obtain permission directly from the copyright holder. To view a copy of this licence, visit http://creativecommons.org/licenses/by/4.0/. The Creative Commons Public Domain Dedication waiver (http://creativecommons.org/publicdomain/zero/1.0/) applies to the data made available in this article, unless otherwise stated in a credit line to the data. 
Conclusions: Overall, preference elicitation approaches have been increasingly applied to mental health services globally in the past 20 years. To date, these methods have been exclusively applied to populations within the field of mental health in high-income countries. Prioritizing patients' needs and preferences is a vital component of patient-centered care - one of the six domains of health care quality. Identifying patient preferences for mental health services may improve quality of care and, ultimately, increase acceptability and uptake of services among patients. Rigorous preference-elicitation approaches should be considered, especially in settings where mental health resources are scarce, to illuminate resource allocation toward preferred service characteristics especially within low-income settings.

Keywords: Conjoint analysis, Discrete choice experiments, Mental health interventions

\section{Background}

Mental disorders are the leading cause of disability and the second leading cause of death globally, accounting for over 276 million disability-adjusted life years and leading to over 9 million deaths annually [1]. The burden of depression, anxiety, substance use, and some neurological disorders is comparable to noncommunicable diseases like cancer and coronary heart disease, more prominently known for their worldwide health impact [2]. Despite this burden, mental health services are scarce in many areas of the world, especially low-andmiddle-income countries [3]. Even when services exist, they may not serve patient and provider needs and be based on either of their preferences to optimize formal health care services.

There is strong evidence from other disease areas (e.g., cancer, HIV, and veteran health services, among others) that services which engage patients from the beginning - during conceptualization of the service - can be highly successful and effective [4]. The global impetus from the Sustainable Development Goals (SDGs) Universal Health Coverage initiative (SDG 3) focuses on the need for services that are accessible, affordable, good quality and acceptable by people for whom these are designed [5]. Correspondingly, taking example of services for adolescents and youth, the World Health Organization (WHO) encourages service provision that is responsive to patient preferences, such as "youth-friendly services" described in the Global Accelerated Action for Health of Adolescents (AA-HA!) guidelines, to encourage uptake and engagement in services [6]. The WHO considers patient-centeredness not only integral to human rights enforcement in health services but also central to developing integrated systems [7].

As mental ill-health becomes increasingly recognized as a global burden, innovations are emerging to provide accessible, affordable, and acceptable prevention, care, and treatment services to the diverse populations faced with mental health issues [8-10]. Information and messages about mental health, preventative services, treatment characteristics, provider approaches, and care provision modalities must continue to evolve based on stakeholder preferences to ensure relevance and desirability. However, patient involvement in shaping mental health practice has been minimal, especially in lowresource settings [11-14].

Despite establishing the need to rigorously elicit patient preferences for healthcare, "precisely how to systematically assess and incorporate patient preferences in the clinical setting remains an area with a need for methodological development" (astutely articulated by Wittink et al) [15]. Multiple methods have been developed and applied to empirically identify preferences. Two widely used quasi-experimental, quantitative approaches made popular by their use in market research and grounded in macroeconomic principles [16] are conjoint analysis (CA) and discrete choice experiments (DCE) DCEs [1719]. Both methods offer rigorous and systematic approaches for eliciting preferences for service or product attributes from customers and stakeholders [20].

Conjoint analyses decompose an intervention into its key attributes, then pose the attributes to patients to understand patient-determined values for each attribute [21, 22]. Similarly, in discrete choice experiments, researchers construct treatment or service options from a set of attributes and posing them to patients in an experimental design to enable independent assessment of preferences for specific attributes in statistical analysis [23]. The methods are grounded in the premise that goods and services are comprised of discrete attributes and that consumers holistically value goods and services based on the collective levels of the attributes [18]. As such, these methods involve posing options for attributes of services to a stakeholder group who select preferred options from a series of choices that pit attributes against each other. Ultimately, conjoint analysis and discrete choice experiments allow for estimation of the relative importance of aspects of the service, trade-offs between attributes made by stakeholders, and overall service satisfaction based on stakeholder preferences.

These methods are increasingly applied to healthcare settings to enable patient input for patient-centered care [18]. CA and DCEs have been successfully applied for patient preference elicitation in multiple areas of 
healthcare, including provider-interactions, health service delivery content and format, and treatment options [18]. Increasingly, CA and DCE methods are applied to mental health service delivery and treatment options. DCEs.

Appropriate and acceptable presentations of mental health services differ between groups such that cultural adaptations should be made for optimal effectiveness $[24,25]$. Especially in settings where few mental health services exist, development of novel albeit multimodal services should directly involve patient informed service development. Additionally, understanding preferences may elucidate patient perception of risks and causes of mental disorder, as well as social determinants driving mental health outcomes. In this way, CA and DCEs offer opportunities to further scientific understanding of mental health underpinnings within communities while illuminating gaps in patient knowledge worthy of attention. CA and DCEs offer rigorous and evidence-based approaches to improving acceptability and reducing barriers to mental health services, especially among hardto-reach populations.

Despite the utility of CA and DCE methods toward improving mental health services, no studies have systematically synthesized information about application of CA and DCE toward preferences in mental health care provision. Understanding where such studies have occurred geographically, the mental health issues to which they were applied, and service and treatment attributes investigated would help identify gaps for further exploration. Further, systematically evaluating the study design components such as the preparatory work utilized, number and type of choices and attributes used, and other methodologic and analytic characteristics may facilitate application of CA and DCE for eliciting preferences in new populations and settings.

Due to the rapid developments in the application of CA and DCEs toward healthcare, specifically for mental health, we considered it timely to conduct a scoping review on applications of CA and DCEs for soliciting and identifying stakeholder preferences for mental health services within the past 20 years globally. We think there is a need to promote their use in global mental health with a focus on LMICs.

DCEs.

Through this scoping review we identified published examples of CA and DCEs for mental health within the literature and mapped their characteristics with the ultimate goal of informing future preference elicitation for mental health services.

\section{Methods}

\section{Identification of eligible studies and search strategy}

We performed a broad search of the literature to identify articles depicting use of CA and DCEs to identify patient and stakeholder preferences for mental health services. Six databases were systematically consulted: Pubmed, CINAHL, PsychInfo, Embase, Cochrane, and Web of Science. Prior to conducting the search, we identified keywords and search terms and organized them appropriately for each database (see Supplementary Table 1). We performed the scoping search in July 2019, yielding 695 total citations (CINAHL: 63, Cochrane: 64, EMBASE: 355, PsychInfo: 61, Pubmed: 67, Web of Science: 85). Endnote X7 Reference Manager was used to manage citations identified. After duplicates $(n=160)$ and citations published before $1990(n=2)$ were removed, 533 citations remained. The PRISMA 2020 Statement Preferred Reporting Items for Systematic reviews and Meta-Analyses extension for Scoping Reviews (PRISMA-ScR) guidelines were followed for this review $[26,27]$.

\section{Selection of literature}

A two-phased approach was used to identify articles included in the review. In phase 1, all 533 article titles and abstracts were assessed by a single reviewer for their consistency with inclusion/exclusion criteria (see Table 1). Articles were included that utilized CA and DCEs methods and sought preferences for mental health service aspects. We excluded articles that did not utilize these methods or that sought preferences for services not related to mental health, as well as non-English language publications. All articles that did not fit the inclusion criteria were excluded. The main reason for exclusion at the full-text review phase was due to CA and DCEs being non-mental health focused.

During phase 2, the remaining articles were reviewed in full-text separately but in parallel by two reviewers for their consistency with inclusion/exclusion criteria. During this phase, articles without full text versions and student dissertations or theses were additionally excluded. Any remaining reviewer disagreement was resolved with collective review of full-text articles and discussion about relevance. Both reviewers had to agree for an article to be excluded. Overall, 30 articles fit scoping review criteria and were identified for synthesis.

\section{Data extraction}

To address our research objective of investigating the applications of CA and DCEs to ascertain key stakeholder preferences for mental health services, understanding individual level service needs and demand characteristics we systematically examined each article for the population studied, geographical location, sample size, mental health service preferences assessed, methods used to design the study, methods used to analyze preferences, and categories/sub-categories of choices presented. Categories for data extraction were informed by 
Table 1 Inclusion/Exclusion criteria for scoping review

\begin{tabular}{|c|c|c|c|}
\hline Phase & Reviewers & Inclusion Criteria & Exclusion Criteria \\
\hline $\begin{array}{l}\text { 1: Titles/abstracts } \\
\text { reviewed }\end{array}$ & Single reviewer & $\begin{array}{l}\text { - Conjoint analysis methods used } \\
\text { - Preferences for mental health services assessed } \\
\text { (e.g., content, format, practitioners, treatment options, etc) }\end{array}$ & $\begin{array}{l}\text { - Non-conjoint analysis methods used } \\
\text { - Preferences for non-mental health ser- } \\
\text { vices assessed } \\
\text { - Non-English language }\end{array}$ \\
\hline $\begin{array}{l}\text { 2: Full-text articles } \\
\text { reviewed }\end{array}$ & $\begin{array}{l}\text { Two, parallel } \\
\text { reviewers }\end{array}$ & Same as above & $\begin{array}{l}\text { - Same as above } \\
\text { - Articles without accompanying full texts } \\
\text { - Dissertation or thesis }\end{array}$ \\
\hline
\end{tabular}

a checklist for developing CA applied to health care settings from the International Society for Pharmacoeconomics and Outcomes Research which helps explain the utility of these methods toward health care improvement (see Table 2). We extracted this information into a comprehensive matrix and assessed the information for emerging patterns and gaps in the utilization of conjoint analysis to evaluate stakeholder preferences for mental health services within existing literature.

\section{Results}

An electronic search yielded a total of 695 titles and abstracts which were judged to be potentially relevant based on title and abstract reading. Of these, 160 records were excluded for being duplicates and 2 were published before 1990. Full texts and abstracts of the remaining 533 articles were reviewed where 480 were excluded because they were not related to mental health. A total of the remaining 53 full-text articles were assessed for

Table 2 Conjoint analysis applications in health: a checklist offered by the International Society for Pharmacoeconomics and Outcomes Research [20]

Research question and hypothesis clarity: A sound and testable hypothesis underpinning a research question that is focusing on some aspect of patient health or care. This hypothesis has to be back by existing literature and grounded through some formative qualitative research. Understanding attributes and levels: Conjoint analysis focuses on elicitation of preferences or values over the range of attributes and levels that define key domains in the conjoint-analysis tasks. The attribute levels should encompass the range that may be salient to participants, even if those levels are hypothetical or not feasible in each context.

Construction of tasks: "Tasks" describe the choice options presented to patients from which they make their selected preference. Within a choice task, attributes and levels may be offered individually or in "profiles" where multiple attributes and levels are offered together to represent a service or product option. Thoughtful construction of tasks is helpful to understand trade-offs better.

Experimental nature of the design: The goal of a conjoint-analysis experimental design is to create a set of tasks that will yield as much statistical information as possible for estimating unbiased, precise preference parameters. In accordance with the experimental nature, the design must be balanced at each level and attribute.

Preference elicitation: Offering participants contextual information including motivation and explanation for the tasks helps in eliciting the right choices. It is critical that the overall design is not cognitively or semantically challenging for the participants. Pretests and expert, key stakeholder consultation is critical here.

Table 2 is taken directly from: Bridges [1] eligibility where 23 articles were excluded because they were either non-CA and non-DCEs or non-peer reviewed. A total 30 articles 30 were ultimately reviewed based on their satisfaction of inclusion criteria.

A flow chart through the different steps of study selection is provided in Fig. 1.

\section{Conjoint analysis/discrete choice experiment characteristics Study location and year}

The studies included were published between 2000 and 2018 , the majority $(21 / 30,70 \%)$ of which were published since 2010. Most studies were conducted in the United States $(11 / 30,37 \%)$ or Canada $(10 / 30,33 \%)$, and all were conducted in high-income settings (Germany: 4/30, 13\%, UK: 3/30, 10\%, Japan: 2/30, 7\%) (Table 3).

\section{Study populations}

Studies most frequently elicited preferences from patient and prospective patient populations $(21 / 30,70 \%)$, others sought preferences from parents of children requiring mental health services $(7 / 30,23 \%)$, and few sought mental health providers and administrators (4/30, 13\%). Some studies included multiple population types. Source populations for the studies ranged widely, with some studies recruiting participants directly from waiting rooms and outpatient health facilities [28-36], some from inpatient services [37-40], some querying university students [41-44], some recruiting from service waitlists (such as those waiting initiation of a service in the Canadian national health system) [45-51], others from provider databases [52] or internet-based health community $[15,53,54]$.

\section{Mental health issues, services, and attributes investigated} Nearly half of the studies sought preferences for mental health services generally without focus on a particular issue or disorder (14/30, 47\%). A quarter focused on preferences for unipolar depression services (8/30, 27\%), and fewer focused on other mental health issues (attention deficit hyperactivity disorder: [3/30, 10\%], addiction/substance use disorder $[2 / 30,7 \%]$, dementia [2/30, $7 \%]$, and bipolar disorder $[1 / 30,3 \%])$. The mental health services of focus for the included studies ranged widely 


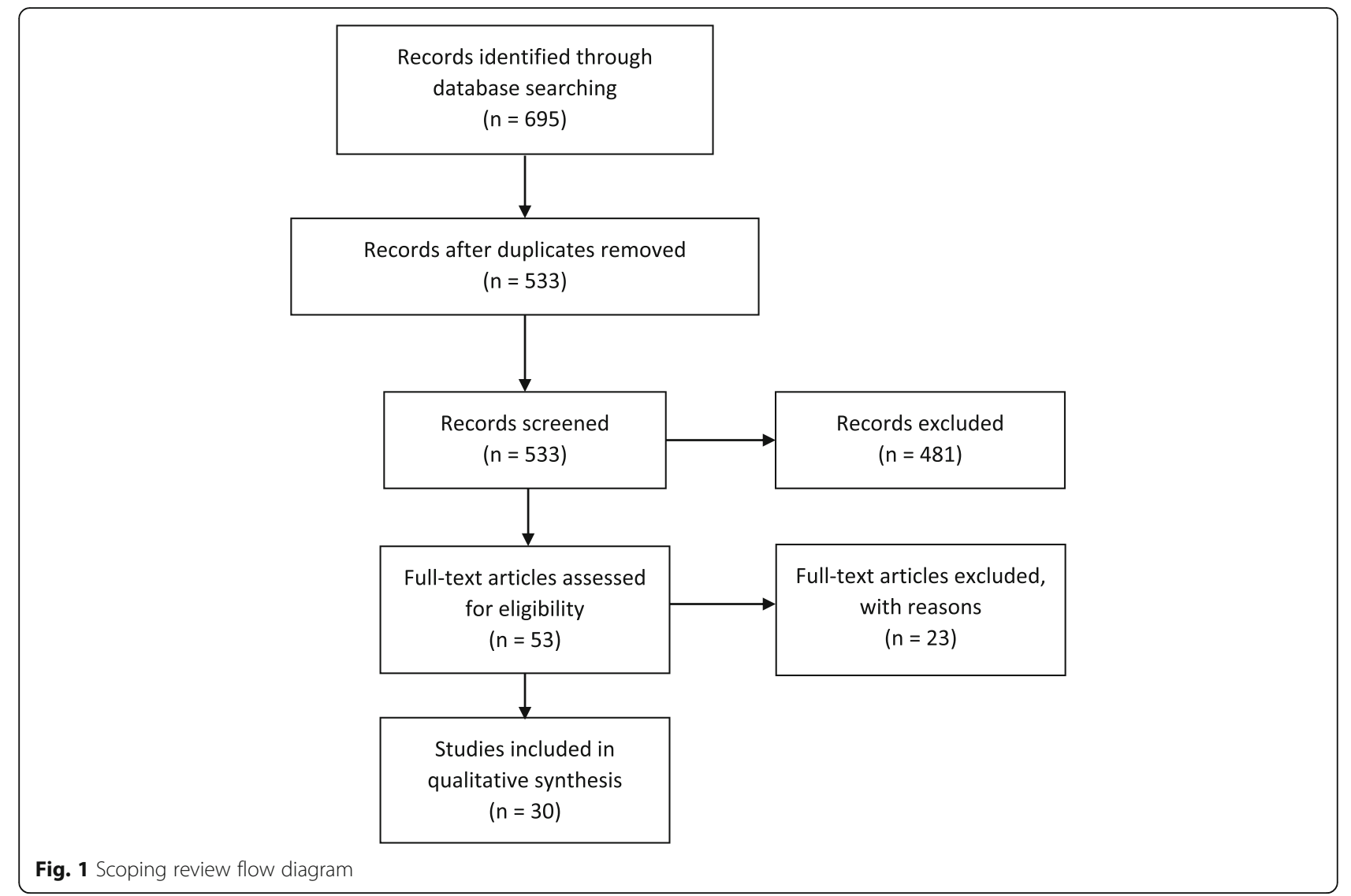

with over half $(17 / 30,57 \%)$ seeking stakeholder preferences for attributes of mental health care and treatment, and others focused on choices for health messages and information $(2 / 30,7 \%)$, prevention and early intervention services $(2 / 30,7 \%)$, child mental health interventions $(4 / 30,13 \%)$ campus-, school-, and communitybased programs $(2 / 30,7 \%)$. One study sought preferences for psychosocial support services $(1 / 30,3 \%)$, one for genetic testing services for dementia $(1 / 30,7 \%)$, and another one for pharmacologic attribute preferences (1/ 30, 7\%). Individual attributes assessed were extremely variable and ranged widely across studies to make further generalizations but depression remains a commonly studied condition.

Due to variability in stakeholder populations assessed, mental health issues explored, and attributes investigated in these CA and DCE studies, we did not synthesize information about patient and provider preferences identified within the CA and DCE studies. Through our systematic review, we aim to facilitate greater understanding of the design and application of CA and DCE studies for use in mental health care settings, thus we focused our results on practical aspects of existing studies. Across the 30 studies included from the last 20 years, we saw encouraging evidence of more recent CA and DCEs building upon methodologic and analytic experience from prior CA and DCEs applied to mental health topics, across varied populations. By identifying this rapidly expanded collection of CA and DCEs applied to mental health, we aim to amplify this trend such that future studies are able to build off of the knowledge accumulated over the past 20 years, expanding the application of CA and DCEs to new populations and settings.

\section{Methodologic design applied to conjoint analysis and discrete choice experiments}

CA and DCEs were employed with nearly equal proportion across the studies included (CA: 16/30, 53\%, DCEs: 14/30, 47\%) (see Table 4). Prior to developing the CA or DCE, 70\% (21/30) of studies conducted qualitative exploration among patients, 50\% (15/30) conducted quantitative exploration, and 43\% (13/20) performed literature, or policy qualitative exploration among policy makers (3\%) (Table 4). About half of studies (53\%) employed ternary choice types, while others used binary $(40 \%)$, or did not specify (13\%). The number of attributes explored ranged from three to more than eight, yet the most often used number was more than 8 (40\%) or 4 (37\%). Studies most frequently posed more than 15 choices to each participant (33\%), while the second most frequent number of choices was 5 or fewer (27\%). Self- 
Table 3 Characteristics of studies using conjoint analysis to elicit stakeholder preferences for mental health services

\begin{tabular}{|c|c|c|}
\hline Characteristic & $\begin{array}{l}\text { Number } \\
(\%)\end{array}$ & Studies \\
\hline \multicolumn{3}{|l|}{ Study participants ${ }^{\mathrm{a}}$} \\
\hline Patients & $21(70 \%)$ & $\begin{array}{l}\text { Dwight-Johnson et al. (2004), Flach et al. (2004), Townend (2000), Townend et al. (2002), } \\
\text { Dwight-Johnson et al. (2013), Wittink et al. (2010), Lee et al. (2014), Fahey et al. (2017), Albus } \\
\text { et al. (2005), Ng-Mak et al. (2018), Zimmermann et al. (2013), Bell et al. (2010), Hajime et al. } \\
\text { (2018), Huang et al. (2014), Becker et al. (2016), Herman et al. (2016), Cunningham et al. (201) } \\
\text { Okumura et al. (2012), Cunningham et al. (2014), Dwight-Johnson et al. (2010), Zipursky et al. } \\
\text { (2017) }\end{array}$ \\
\hline Providers & $4(13 \%)$ & Riepe et al. (2017), Becker et al. (2016), Cunningham et al. (2018), Cunningham et al. (2012) \\
\hline Parents/caregivers & $7(23 \%)$ & $\begin{array}{l}\text { Wymbs et al. (2018), Fegert et al. (2011), Waschbusch et al. (2011), Becker et al. (2016), } \\
\text { Cunningham et al. (2015), Cunningham et al. 92,013), Cunningham et al. (2008) }\end{array}$ \\
\hline
\end{tabular}

\section{Country}

USA

Canada

\section{Germany}

UK

Japan

Year

2000-2010

2011-2019

\section{Method}

Conjoint analysis

DCE

\section{Mental health issue}

Mental health general

Unipolar depression

ADHD

Addiction/substance use

Dementia

Bipolar disorder

\section{Attributes investigated}

Adult care and treatment
11 (37\%) Wymbs et al. (2018), Dwight-Johnson et al. (2004), Flach et al. (2004), Dwight-Johnson et al. (2013), Wittink et al. (2010), Lee et al. (2014), Waschbusch et al. (2011), Ng-Mak et al. (2018), Huang et al. (2014), Dwight-Johnson et al. (2010), Herman et al. (2016)

10 (33\%) Bell et al. (2010), Zipursky et al. (2017), Becker et al. (2016), Cunningham et al. (2018), Cunningham et al. (2017), Cunningham et al. (2015), Cunningham et al. (2014), Cunningham et al. (2013), Cunningham et al. (2012), Cunningham et al. (2008)

4 (13\%) Riepe et al. (2017), Albus et al. (2005), Zimmermann et al. (2013)

3 (10\%) Townend (2000), Townend et al. (2002), Fahey et al. (2017)

2 (7\%) Hajime et al. (2018), Okumura et al. (2012)

9 (30\%) Townend (2000), Townend et al. (2002), Dwight-Johnson et al. (2004), Flach et al. (2004), Albus et al. (2005), Cunningham et al. (2008), Wittink et al. (2010), Bell et al. (2010), Dwight-Johnson et al. (2010)

21 (70\%) Fegert et al. (2011), Waschbusch et al. (2011), Okumura et al. (2012), Dwight-Johnson et al. (2013), Zimmermann et al. (2013), Cunningham et al. (2013), Lee et al. (2014), Huang et al. (2014, Cunningham et al. (2014), Cunningham et al. (2015), Becker et al. (2016), Herman et al. (2016), Riepe et al. (2017), Fahey et al. (2017), Zipursky et al. (2017), Cunningham et al. (2017), Wymbs (2018), Ng-Mak et al. (2018), Hajime (2018), Cunningham et al. (2018)

16 (53\%) Townend (2000), Townend et al. (2002), Dwight-Johnson et al. (2004), Flach et al. (2004), Albus et al. (2005), Bell et al. (2010), Dwight-Johnson et al. (2010), Okumura et al. (2012), DwightJohnson et al. 2013), Zimmermann et al. (2013), Lee et al. (2014), Huang et al. (2014), Riepe et al. (2017), Fahey et al. (2017), Wymbs et al. (2018), Hajime et al. (2018)

14 (47\%) Cunningham et al. (2008), Wittink et al. (2010), Fegert et al. (2011), Waschbusch et al. (2011), Cunningham (2012), Cunningham et al. (2013), Cunningham et al. (2014), Becker et al. (2016), Herman et al. (2016), Zipursky et al. (2017), Cunningham et al. (2017), Ng-Mak et al. (2018), Cunningham et al. (2018), Flach et al. (2004)

14 (47\%) Townend (2000), Townend et al. (2002), Albus et al. (2005), Cunningham et al. (2008), Cunningham et al. (2013), Lee et al. (2014), Cunningham et al. (2014), Cunningham et al. (2015), Becker et al. (2016), Herman et al. (2016), Zipursky et al. (2017), Cunningham et al. (2017), Hajime et al. (2018), Cunningham et al. (2018)

8 (27\%) Dwight-Johnson et al. (2004), Wittink et al. (2010), Bell et al. (2010), Dwight-Johnson et al. (2010), Okumura et al. (2012), Dwight-Johnson et al. (2013), Zimmermann et al. (2013), Riepe et al. (2017)

3 (10\%) Fegert et al. (2011), Waschbusch et al. (2011), Wymbs et al. (2018)

2 (7\%) Flach et al. (2004), Cunningham et al. (2012)

2 (7\%) Huang et al. (2014), Fahey et al. (2017)

1 (3\%) Ng-Mak et al. (2018)

17 (57\%) Townend (2000), Townend et al. (2002), Dwight-Johnson et al. (2004), Flach et al. (2004), Wittink et al. (2010), Dwight-Johnson et al. (2010), Fegert et al. (2011), Waschbusch et al. (2011), Okumura et al. (2012), Cunningham et al. (2012), Dwight-Johnson et al. (2013), Zimmermann et al. 
Table 3 Characteristics of studies using conjoint analysis to elicit stakeholder preferences for mental health services (Continued)

\begin{tabular}{|c|c|c|}
\hline Characteristic & $\begin{array}{l}\text { Number } \\
(\%)\end{array}$ & Studies \\
\hline & & (2013), Lee et al. (2014), Herman et al. (2016), Riepe et al. (2017), Zipursky et al. (2017) \\
\hline Child mental health interventions & $4(13 \%)$ & $\begin{array}{l}\text { Cunningham et al. (2008), Cunningham et al. (2013), Cunningham et al. (2015), Cunningham } \\
\text { et al. (2018) }\end{array}$ \\
\hline $\begin{array}{l}\text { Early mental health intervention } \\
\text { services/prevention services }\end{array}$ & $2(7 \%)$ & Becker et al. (2016), Hajime et al. (2018) \\
\hline Messaging/information & $2(7 \%)$ & Bell et al. (2010), Cunningham et al. (2014) \\
\hline $\begin{array}{l}\text { Campus/school/community-based } \\
\text { services }\end{array}$ & $2(7 \%)$ & Cunningham et al. (2017), Wymbs et al. (2018) \\
\hline Psychosocial support services & $1(3 \%)$ & Albus et al. (2005) \\
\hline Genetic testing & $1(3 \%)$ & Huang et al. (2014) \\
\hline Pharmacologic attributes & $1(3 \%)$ & Ng-Mak et al. (2018) \\
\hline
\end{tabular}

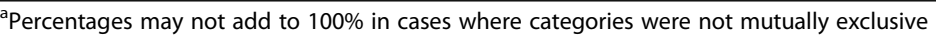

completed questionnaires were the most common form of administering CA and DCEs (80\%), while five studies administered questionnaires by a study staff member. Sample sizes for the studies ranged from 29 to 2469, with $27 \%(8 / 30)$ of studies having 100 participants or fewer, 37\% (11/30) having sample sizes between 101 and 300 and 33\% (10/30) having over 300 participants.

The majority of CA and DCEs (57\%) employed main effects and interactions in their study design plans. The most common methodologic approach to designing the choice tasks was use of orthogonal design with Bayesian analysis. Across the 30 studies, the total number of choice tasks posed within CA and DCEs ranged from 10 to over 150 . Half of the analyses $(15 / 30,50 \%)$ utilized Sawtooth software, while SPSS was the second mostutilized statistical software (20\%). Other analyses utilized SAS (13\%), Stata (3\%), R (3\%), and many studies used multiple of the aforementioned statistical packages.

Similarly, most studies utilized multiple statistical analysis methods with the most frequently used method as logistic regression $(12 / 30,40 \%)$, latent class analysis as the second most used (10/30, 33\%), hierarchical Bayes estimation methods were also commonly used $(8 / 30$, $27 \%)$. Other methods included ordinary least squares regression (6/30, 20\%), chi-squared, ANOVA, and MANOVA tests $(7 / 30,23 \%)$, and ordered probit regression (4/ $30,13 \%)$.

\section{Discussion}

Our scoping review of CA and DCEs attempted to elicit stakeholder preferences and individual level service needs and demand for mental health services. We summarize the use of these preference elicitation methods to date towards finding solutions towards mental health service design and management given the increasing global health burden of mental health disorders [55]. We identified few $(n=30)$ applications of these methods in this context and highlighted depression services as the mental health disorder toward which they have been most frequently utilized. All existing studies took place in high-income settings, showcasing a gap in current application and an opportunity for expansion to low- and middle-income settings. Such settings may face a scarcity of mental health resources such that prioritization based on patient-centered and providerinformed preferences could aid in tailoring services to optimize access and acceptability. Further, applications to date have mostly focused on adult mental health care and treatment, with fewer studies focused on child health. Two studies focused on preferences from university students highlighting potential utility in seeking mental health preferences among adolescent and young adult groups - an age category at higher risk for mental health issues globally and a demographic for whom mental health promotion and prevention services are important. Our results add to the limited literature regarding an appraisal of well-developed methods to improve patient-centeredness of mental health services using rigorous sequential mixed methods. Existing evidence demonstrates feasibility and increasing interest in seeking stakeholder preferences for mental health services, and can be used to inform future studies which expand the application of these methods to other contexts and populations facing mental health problems.

\section{Potential of CA and DCEs in mental health research}

The need to address behavioral and psychosocial problems globally is more urgent than ever and is gaining recognition within global health goal-setting such as health systems strengthening to address the noncommunicable disease burden (including mental disorders) within the Sustainable Development Goals [5]. Patient and provider preference elicitation to inform intervention development and evaluation should be considered an integral component of quality of care and service development globally. Recognizing our patients and 
Table 4 Methodologic design employed by conjoint analyses/discrete choice experiments to elicit stakeholder preferences for mental health services

\begin{tabular}{|c|c|c|c|}
\hline Design Aspect & Specification & N (\%) & Studies \\
\hline Preparatory ${ }^{a}$ work & Literature review & $13(43 \%)$ & $\begin{array}{l}\text { Dwight-Johnson et al. (2013), Dwight-Johnson et al. (2010), Ng-Mak (2018), } \\
\text { Wymbs (2018), Townend (2000), Fach et al. (2004), Fegert et al. (2011), } \\
\text { Okumura et al. (2012), Lee et al. (2014), Huang et al. (2014), Becker et al. } \\
\text { (2016), Fahey et al. (2017), Zipursky et al. (2017) }\end{array}$ \\
\hline
\end{tabular}

Patient qualitative work $21(70 \%)$

Policy maker/provider qualitative work

Quantitative work

$3(10 \%)$

$15(50 \%)$

Albus et al. (2005), Bell et al. (2010), Cunningham et al. (2008), Cunningham et al. (2012), Cunningham et al. (2013), Cunningham et al. (2014), Cunningham et al. (2018), Cunningham et al. (2015), Dwight-Johnson et al. (2013), Dwight-Johnson et al. (2010), Dwight-Johnson et al. (2004), Herman et al. (2016), Ng-Mak et al. (2018), Wittink et al. (2010), Wymbs (2018), Zimmerman et al. (2013), Townend (2000), Townend et al. (2002), Fegert et al. (2011), Okumura et al. (2012), Becker et al. (2016)

Cunningham et al. (2017), Cunnigham et al. (2018), Becker et al. (2016)

Albus et al. (2005), Cunningham et al. (2008), Cunningham et al. (2012) Cunningham et al. (2013), Cunningham et al. (2014), Cunningham et al. (2017), Cunningham et al. (2018), Dwight-Johnson et al. (2013), DwightJohnson et al. (2010), Ng-Mak et al. (2018), Riepe et al. (2017), Wymbs (2018), Zimmerman et al. (2013), Townend et al. (2002), Becker et al. (2016)

Not specified $\quad 2(7 \%)$

Type of Choice Binary

Waschbusch et al. (2011), Hajime (2018)

Ng-Mak et al. (2018), Zimmerman et al. (2013), Townend et al. (2002), Dwight-Johnson et al. (2004), Wittink et al. (2010), Bell et al. (2010), DwightJohnson et al. (2010), Fegert et al. (2011), Dwight-Johnson et al. (2013), Lee et al. (2014), Cunningham et al. (2015), Hajime (2018)

Ternary

$16(53 \%)$

Albus et al. (2005), Becker et al. (2016), Cunningham et al. (2008),

Cunningham et al. (2012), Cunningham et al. (2013), Cunningham et al. (2014), Cunningham et al. (2017), Cunningham et al. (2018), Herman et al. (2016), Wymbs (2018), Zipursky et al. (2017), Flach et al. (2004), Wittink et al. (2010), Waschbusch et al. (2011), Okumura et al. (2012), Fahey et al. (2017)

Not specified $\quad 4(13 \%)$

Number of Attributes

2

3

4

$1(3 \%)$

$2(7 \%)$

$11(37 \%)$

Townend (2000), Huang et al. (2014), Becker et al. (2016), Riepe et al. (2017)

Flach et al. (2004)

Okumura et al. (2012), Huang et al. (2014)

Albus et al. (2005), Becker et al. (2016), Cunningham et al. (2008), Cunningham et al. (2012), Cunningham et al. (2013), Cunningham et al. (2014), Cunningham et al. (2017), Cunningham et al. (2018), Wittink et al. (2010), Dwight-Johnson et al. (2013), Fahey et al. (2017)

$5+1(3 \%)$

More than 8

Not specified

Number of choices per individual
$8(27 \%)$

5 or less

6-10

$7(23 \%)$

11-15

More than 15
$4(13 \%)$

$1(3 \%)$

$2(7 \%)$

$12(40 \%)$

$3(10 \%)$

Lee et al. (2014)

Ng-Mak et al. (2018), Dwight-Johnson et al. (2004), Fegert et al. (2011), Hajime (2018)

Dwight-Johnson et al. (2010),

Herman et al. (2016), Townend et al. (2002)

Bell et al. (2010), Waschbusch et al. (2011), Cunningham et al. (2013), Cunningham et al. (2014), Cunningham et al. (2017), Cunningham et al. (2018), Cunningham et al. (2015), Flach et al. (2004), Wittink et al. (2010), Wymbs (2018), Zimmerman et al. (2013), Zipursky et al. (2017),

Townend (2000), Becker et al. (2016), Riepe et al. (2017)

Cunningham et al. (2008), Cunningham et al. (2013), Fahey et al. (2017), Herman et al. (2016), Okumura et al. (2012), Townend et al. (2002), Zimmerman et al. (2013), Zipursky et al. (2017)

Albus et al. (2005), Dwight-Johnson et al. (2010), Flach et al. (2004), Fegert et al. (2011), Dwight-Johnson et al. (2013), Lee et al. (2014), Fahey et al. (2017)

Dwight-Johnson et al. (2004), Huang et al. (2014), Hajime (2018)

10 (33\%) Becker et al. (2016), Cunningham et al. (2008), Huang et al. (2014), Wittink et al. (2010), Bell et al. (2010), Waschbusch et al. (2011), Cunningham et al. (2012), Cunningham et al. (2017), Cunningham et al. (2015), Cunningham et al. (2018) 
Table 4 Methodologic design employed by conjoint analyses/discrete choice experiments to elicit stakeholder preferences for mental health services (Continued)

\begin{tabular}{|c|c|c|c|}
\hline Design Aspect & Specification & N (\%) & Studies \\
\hline & Not specified & $3(10 \%)$ & Townend (2000), Riepe et al. (2017), Ng-Mak et al. (2018) \\
\hline \multirow[t]{2}{*}{ Administration of survey } & $\begin{array}{l}\text { Self-completed } \\
\text { questionnaire }\end{array}$ & $24(80 \%)$ & $\begin{array}{l}\text { Albus et al. (2005), Cunningham et al. (2008), Cunningham et al. (2018), } \\
\text { Cunningham et al. (2012), Cunningham et al. (2013), Cunningham et al. } \\
\text { (2014), Cunningham et al. (2015), Cunningham et al. (2017), Dwight-Johnson } \\
\text { et al. (2004), Becker et al. (2016), Herman et al. (2016), Townend (2000), } \\
\text { Townend et al. (2002), Waschbusch et al. (2011), Zimmerman et al. (2013), } \\
\text { Wittink et al. (2010), Bell et al. (2010), Fegert et al. (2011), Okumura et al. } \\
\text { (2012), Huang et al. (2014), Zipursky et al. (2017), Wymbs (2018), Ng-Mak } \\
\text { et al. (2018), Hajime (2018) }\end{array}$ \\
\hline & Interview administered & $5(17 \%)$ & $\begin{array}{l}\text { Fahey et al. (2017), Lee et al. (2014), Riepe et al. (2017), Dwight-Johnson } \\
\text { et al. (2010), Dwight-Johnson et al. (2013) }\end{array}$ \\
\hline \multirow[t]{3}{*}{ Sample size } & $10-100$ & $8(27 \%)$ & $\begin{array}{l}\text { Townend (2000), Townend et al. (2002), Dwight-Johnson et al. (2004), Flach } \\
\text { et al. (2004), Wittink et al. (2010), Dwight-Johnson et al. (2013), Riepe et al. } \\
\text { (2017), Wymbs (2018) }\end{array}$ \\
\hline & $101-300$ & $11(37 \%)$ & $\begin{array}{l}\text { Albus et al. (2005), Bell et al. (2010), Fegert et al. (2011), Waschbusch et al. } \\
\text { (2011), Zimmermann et al. (2013), Lee et al. (2014), Huang et al. (2014), } \\
\text { Fahey et al. (2017), Zipursky et al. (2017), Ng-Mak et al. (2018), Hajime (2018) }\end{array}$ \\
\hline & $>300$ & $12(40 \%)$ & $\begin{array}{l}\text { Cunningham et al. (2008), Dwight-Johnson et al. (2010), Okumura et } \\
\text { al. (2012), Cunningham et al. (2012), Cunningham et al. (2013), Cunningham } \\
\text { et al. (2014), Cunningham et al. (2015), Becker et al. (2016), Herman et al. } \\
\text { (2016), Cunningham et al. (2017), Cunningham et al. (2018), Okumura et } \\
\text { al. (2012) }\end{array}$ \\
\hline \multirow[t]{4}{*}{ Design Plan } & Main effects only & $4(13 \%)$ & $\begin{array}{l}\text { Townend et al. (2002), Dwight-Johnson et al. (2004), Fegert et al. (2011), } \\
\text { Lee et al. (2014) }\end{array}$ \\
\hline & Main effects + Interactions & $17(57 \%)$ & $\begin{array}{l}\text { Albus et al. (2005), Cunningham et al. (2008), Cunningham et al. (2012), } \\
\text { Becker et al. (2016), Cunningham et al. (2013), Cunningham et al. (2014), } \\
\text { Cunningham et al. (2017), Cunningham et al. (2018), Cunningham et al. } \\
\text { (2015), Herman et al. (2016), Ng-Mak et al. (2018), Waschbusch et al. (2011), } \\
\text { Wittink et al. (2010), Zimmerman et al. (2013), Zipursky et al. (2017), Dwight- } \\
\text { Johnson et al. (2010), Riepe et al. (2017) }\end{array}$ \\
\hline & $\begin{array}{l}\text { Not clearly reported in } \\
\text { the methods but main } \\
\text { effects only reported }\end{array}$ & $6(20 \%)$ & $\begin{array}{l}\text { Dwight-Johnson et al. (2013), Flach et al. (2004), Bell et al. (2010), Fahey } \\
\text { et al. (2017), Wymbs (2018), Hajime (2018) }\end{array}$ \\
\hline & $\begin{array}{l}\text { Not clearly reported in } \\
\text { the methods and unclear } \\
\text { in the results }\end{array}$ & $2(7 \%)$ & Huang et al. (2014), Townend (2000) \\
\hline \multirow[t]{11}{*}{ Analytic software } & Sawtooth software & $15(50 \%)$ & $\begin{array}{l}\text { Albus et al. (2005), Becker et al. (2016), Bell et al. (2010), Cunningham et al. } \\
\text { (2008), Cunningham et al. (2012), Cunningham et al. (2013), Cunningham } \\
\text { et al. (2014), Cunningham et al. (2015), Cunningham et al. (2017), } \\
\text { Cunningham et al. (2018), Herman et al. (2016), Ng-Mak et al. (2018), } \\
\text { Waschbusch et al. (2011), Zimmerman et al. (2013), Wymbs (2018) }\end{array}$ \\
\hline & Latent gold choice & $4(13 \%)$ & $\begin{array}{l}\text { Becker et al. (2016), Cunningham et al. (2017), Cunningham et al. (2015), } \\
\text { Zipursky et al. (2017) }\end{array}$ \\
\hline & SPEED & $2(7 \%)$ & Townend et al. (2002), Fegert et al. (2011) \\
\hline & SPSS & $6(20 \%)$ & $\begin{array}{l}\text { Dwight-Johnson et al. (2013), Fahey et al. (2017), Lee et al. (2014), Dwight- } \\
\text { Johnson et al. (2004), Lee et al. (2014), Hajime (2018) }\end{array}$ \\
\hline & SAS & $4(13 \%)$ & $\begin{array}{l}\text { Dwight-Johnson et al. (2010), Huang et al. (2014), Ng-Mak et al. (2018), } \\
\text { Wittink et al. (2010) }\end{array}$ \\
\hline & Stata & $1(3 \%)$ & Flach et al. (2004) \\
\hline & Mplus & $1(3 \%)$ & Okumura et al. (2012) \\
\hline & $\mathrm{R}$ & $1(3 \%)$ & Okumura et al. (2012) \\
\hline & Atlas.ti & $1(3 \%)$ & Ng-Mak et al. (2018) \\
\hline & MATLAB & $1(3 \%)$ & Riepe et al. (2017) \\
\hline & Not Reported & $1(3 \%)$ & Townend (2000) \\
\hline
\end{tabular}


community stakeholders as experts in their own treatment and service needs empowers them to take part in designing care that is acceptable, appropriate, and desirable. Service areas such as psychological and psychiatric services which may be underdeveloped and stigmatized in many settings could especially benefit from patientinformed alternatives, which may encourage utilization of services and, ultimately, alleviation of mental health burden. Such methods might also help us develop programs and services that may mitigate stigma and routinely experienced barriers to care. Here is an example of a DCE study that could give pointers to what patients might look forward to and inconveniences might be willing to overlook A study from South Africa echoed a similar sentiment based on a DCE looking at public health care in which they found that communities were prepared to tolerate public sector health service characteristics such as a long waiting time, poor staff attitudes and lack of direct access to doctors if they received the medicine they need, a thorough examination and a clear explanation of the diagnosis and prescribed treatment from health professionals [56].

\section{Adapting and tailoring mental health interventions based on patient preferences}

Conjoint methods sharpen the focus on "what it is about treatment" that drives preferences and provides specific guideposts for how to design packages of treatment that are patient-centered. A number of studies covered depression and psychosocial support [15, 28-33, 35, 37$40,42,43,53,54,57-59]$ from the premise that theoretical assimilation of intervention or treatment preference characteristics might vary from real life choices and concerns. A DCE is a quantitative tool that measures the weight of different factors that affect a decision. Participants are presented with two hypothetical scenarios to choose between. Some studies found that the patients expected more personal support from healthcare providers, including flexible working hours and higher quality of patient-provider relationships [60]. Preference elicitation is a key component of the treatment engagement process, improving understanding of which treatment types or strategies best support the priorities of the patient population and, thus improve their outcomes while bolstering their connection to care. Choices prioritized by patients for mental health services may illuminate their own conceptualizations of mental health issues which may highlight opportunities to utilize key health messages for psychotherapeutic interventions. Studies identified in this scoping review showcase that low literacy populations can be effectively included in preference elicitation exercises using simple visualizations and choice tasks that are broken down into basic categories. Other studies demonstrated that patient-preferences identified with conjoint analysis or discrete choice experiments could be used in conjunction with information about existing services, input from healthcare professionals, and qualitative interviews with patients to arrive at a more comprehensive plan for intervention and service development. Importantly, these methods may help serve the needs of diverse populations by informing appropriate and effective mental health services tailored to unique sub-groups. Discrete choice experiments and conjoint analysis might be useful to inform the development of tools to assist shared decision making in psychiatry [61]. Similar ideas were expressed in a DCE carried in Tanzania focused on maternal health care which found that care quality, both technical and interpersonal, was more important than clinic inputs such as equipment and cleanliness [62].

\section{Incorporating preferences of mental health specialists for sustainable capacity and leadership}

Our findings identified examples where conjoint analysis and discrete choice experiments were used to identify nuanced barriers and needs for capacity building among health providers and mental health specialists $[33,36$, $52,63]$. Implementation of evidence-based psychological and psychiatric interventions is complex, thus using quantitative preference elicitation methods to understand service provision processes at the administration, health system, and provider levels could streamline the complexity. Studies from our scoping review identified the desire from mental health providers and administrators for enhanced supervisory support, local decision control in treatment approaches, improved training in psychopathology, more leadership and flexibility in implementation processes, and further training opportunities. Overall, these methods may offer opportunities to improve service evaluation and health system feedback loops via input from health providers and administrators to improve quality of mental health service provision.

\section{Strengthening health systems to deliver patient-centered mental health services}

As the need for effective mental health services is increasingly recognized globally, methods to ensure that such services are relevant and responsive to the needs of patient populations are essential. Rigorous, quantitative approaches to ascertaining input from stakeholders, such as conjoint analysis and discrete choice experiments, have been specifically recommended for integrating mental health services within health systems in low- and middle-income countries [64]. Individual level patient and provider preferences that are identified and incorporated into design and implementation of mental health services synergistically strengthen provision. By seeking contributions from populations served, use of these 
methods improves appropriateness and desirability of services which may improve equity in mental health care. Additionally, the development of knowledge transfer strategies that align the preferences of professionals with those of the families they serve will go a long way in strengthening the system and services [65].

\section{Limitations}

This scoping review was limited to peer-reviewed, published literature; thus, we did not account for conjoint analyses or discrete choice experiments for mental health service preferences reported in other sources. Further, we limited our review to studies available in English language, thus we may have missed findings from other settings published in other languages. Despite these limitations, we feel we were able to achieve our goal of scoping applications of conjoint analysis and DCEs for preference elicitation regarding mental health services through this review.

\section{Conclusions and future directions}

The objective of this scoping review was to describe existing applications of conjoint analysis and discrete choice experiments for eliciting stakeholder preferences, individual patient and provider level for mental health services within published literature. We found that conjoint analysis and discrete choice experiments have been increasingly used over the past 20 years to identify preferences from diverse populations and a range of mental health issues and services. All conjoint analyses identified for this scoping review were performed within highincome countries, yet a few were performed within lowincome populations in those settings. Conjoint analysis and discrete choice experiments have been shown as effective methods for eliciting preferences for mental health services within diverse settings, illustrating a promising approach to increasing patient-centered mental health care. Future applications of such methods should be performed within low- and middle-income countries to assess the performance of this methodology within settings where patient involvement in care is traditionally low and appropriate mental health services are lacking. Ultimately, we assert that application of preference elicitation methods such as conjoint analysis and discrete choice experiments should be applied to mental health services among populations globally to expand utilization and reduce mental health burden.

\footnotetext{
Abbreviations

CA: Conjoint analysis; DCE: Discrete choice experiments; HIV: Human immunodeficiency virus; SDGs: Sustainable Development Goals; W.H.O: World Health Organization; AA-HA: Accelerated Action for Health of Adolescents; PRISMA-ScR: Preferred Reporting Items for Systematic reviews and MetaAnalyses extension for Scoping Reviews; CINAHL: Cumulative Index to Nursing and Allied Health Literature; EMBASE: Excerpta Medica dataBASE; ANOVA: Analysis of Variance; MANOVA: Multivariate analysis of variance
}

\section{Supplementary Information}

The online version contains supplementary material available at https://doi. org/10.1186/s12913-021-06499-w.

Additional file 1: Supplementary Table 1. Search terms per database searched.

\section{Acknowledgements}

Authors would like to thank Jurgen Unutzer for introducing us to these methods.

\section{Ethical standards}

The authors assert that all procedures contributing to this work comply with the ethical standards of the relevant national and institutional committees on human experimentation and with the Helsinki Declaration of 1975, as revised in 2008 .

\section{Authors' contributions}

$\mathrm{AL}$ - Conception of the study, study design, implementation, interpretation of data; drafting and revising the paper, approval of the final draft, overall oversight. AT- Study design, Data quality control, interpretation of the data, literature review and initial drafting. MK.-. Conception of the study, study design, implementation and interpretation of data; literature review and manuscript revision and approval of the final draft.

\section{Funding}

Research reported in this publication was supported by the Fogarty International Center of the National Institutes of Health under Award Number K43TW010716, which also supported the contributions of MK to this work. AL is supported by the National Institutes of Health under Award Number F31HD101149. The content is solely the responsibility of the authors and does not necessarily represent the official views of the National Institutes of Health.

\section{Availability of data and materials}

The datasets used and/or analyzed during the current study available from the corresponding author on reasonable request.

\section{Declarations}

Ethics approval and consent to participate Not applicable.

\section{Consent for publication}

Not applicable.

\section{Competing interests}

To the best of our knowledge, no conflict of interest, financial or other, exists. All the authors read and approved the manuscript.

\section{Author details}

${ }^{1}$ Department of Global Health, University of Washington, Seattle, WA 98195, USA. ${ }^{2}$ IKUZE AFRICA, Nairobi 00100, Kenya. ${ }^{3}$ Department of Psychiatry, University of Nairobi, (47074), Nairobi 00100, Kenya.

Received: 22 November 2020 Accepted: 4 May 2021

Published online: 18 June 2021

References

1. Bridges JF, Hauber AB, Marshall D, Lloyd A, Prosser LA, Regier DA, et al. Conjoint analysis applications in health--a checklist: a report of the ISPOR Good Research Practices for Conjoint Analysis Task Force. Value Health. 2011:14(4):403-13.

2. Feigin VL, Nichols E, Alam T, Collaborators GN. Global, regional, and national burden of neurological disorders, 1990-2016: a systematic analysis for the Global Burden of Disease Study 2016. Lancet Neurol. 2019;18(5):459-80.

3. Patel V. Mental health in low- and middle-income countries. Br Med Bull. 2007:81-82:81-96 
4. Beusterien KM, Dziekan K, Flood E, Harding G, Jordan JC. Understanding patient preferences for HIV medications using adaptive conjoint analysis: Feasibility assessment. Value Health. 2005;8(4):453-61.

5. Kieny MP, Bekedam H, Dovlo D, Fitzgerald J, Habicht J, Harrison G, et al. Strengthening health systems for universal health coverage and sustainable development. Bull World Health Organ. 2017;95(7):537-9.

6. (WHO) WHO. Global Accelerated Action for the Health of Adolescents (AAHA)! 2017.

7. Organization WH. WHO global strategy on integrated people-centred health services 2016-2026. 2015.

8. Magnabosco JL. Innovations in mental health services implementation: a report on state-level data from the U.S. Evidence-Based Practices Project. Implement Sci. 2006;1(1):13.

9. Kimberly J, Cook JM. Organizational Measurement and the Implementation of Innovations in Mental Health Services. Adm Policy Ment Health Ment Health Serv Res. 2008;35(1):11-20.

10. Hollis C, Morriss R, Martin J, Amani S, Cotton R, Denis M, et al. Technological innovations in mental healthcare: harnessing the digital revolution. $\mathrm{Br} J$ Psychiatry. 2018;206(4):263-5.

11. Mitton C, Smith N, Peacock S, Evoy B, Abelson J. Public participation in health care priority setting: a scoping review. Health Policy (Amsterdam, Netherlands). 2009;91:219-28.

12. Tambuyzer $\mathrm{E}$, Pieters $\mathrm{G}$, Van Audenhove C. Patient involvement in mental health care: one size does not fit all. Health Expect. 2014;17(1):138-50.

13. Ng C-J, Lee P-Y, Lee Y-K, Chew B-H, Engkasan JP, Irmi Z-I, et al. An overview of patient involvement in healthcare decision-making: a situational analysis of the Malaysian context. BMC Health Serv Res. 2013;13(1):408.

14. Armstrong N, Herbert G, Aveling E-L, Dixon-Woods M, Martin G. Optimizing patient involvement in quality improvement. Health Expect. 2013;16(3):e3647.

15. Wittink MN, Cary M, TenHave T, Baron J, Gallo JJ. Towards patient-centered care for depression: Conjoint methods to tailor treatment based on preferences. Patient. 2010;3(3):145-57.

16. Green P. On the design of choice experiments involving multifactor alternatives. J Consum Res. 1974;1(2):61-8.

17. Ryan M. Discrete choice experiments in health care; 2004

18. Ryan M, Farrar S. Using conjoint analysis to elicit preferences for health care. BMJ. 2000;320(7248):1530-3.

19. Louviere JJ, Flynn TN, Carson RT. Discrete Choice Experiments Are Not Conjoint Analysis. J Choice Model. 2010;3(3):57-72.

20. Green P, Krieger AM, Wind Y. Thirty years of conjoint analysis: reflections and prospects: interfaces; 2001.

21. Bridges JF, Hauber AB, Marshall D, Lloyd A, Prosser LA, Regier DA, et al. Conjoint analysis applications in health--a checklist: a report of the ISPOR Good Research Practices for Conjoint Analysis Task Force. Value Health. 2011;14(4).

22. Ryan M, Farrar S. Using conjoint analysis to elicit preferences for health care. BMJ (Clinical research ed). 2000;320(7248):1530-3. https://doi.org/10.1136/ bmj.320.7248.1530.

23. Lancsar E, Louviere J. Conducting discrete choice experiments to inform healthcare decision making: a user's guide. PharmacoEconomics. 2008;26(8): 661-77. https://doi.org/10.2165/00019053-200826080-00004 PMID: 18620460.

24. Whaley AL, Davis KE. Cultural competence and evidence-based practice in mental health services: A complementary perspective. Am Psychol. 2007; 62(6):563-74.

25. Griner D, Smith TB. Culturally adapted mental health intervention: A metaanalytic review. Psychotherapy (Chic). 2006r;43(4):531-48. https://doi.org/10.1 037/0033-3204.43.4.531. PMID: 22122142.

26. Tricco A, Lillie E, Zarin W, O'Brien $\mathrm{K}$, Colquhoun $\mathrm{H}$, Levac D, et al. PRISMA extension for scoping reviews (PRISMA-SCR): checklist and explanation. Ann Intern Med. 2018;169(7):467-73.

27. Page MJ, MCKenzie JE, Bossuyt PM, Boutron I, Hoffmann TC, Mulrow CD, et al. The PRISMA 2020 statement: an updated guideline for reporting systematic reviews. 2021

28. Dwight-Johnson M, Lagomasino IT, Aisenberg E, Hay J. Using conjoint analysis to assess depression treatment preferences among low-income Latinos. Psychiatr Serv (Washington, DC). 2004;55(8):934-6.

29. Dwight Johnson M, Apesoa-Varano C, Hay J, Unutzer J, Hinton L. Depression treatment preferences of older white and Mexican origin men. Gen Hosp Psychiatry. 2013;35(1):59-65.
30. Albus C, Schmeißer N, Salzberger B, Fätkenheuer G. Preferences regarding medical and psychosocial support in HIV-infected patients. Patient Educ Couns. 2005;56(1):16-20.

31. Zimmermann TM, Clouth J, Elosge M, Heurich M, Schneider $E$, Wilhelm $\mathrm{S}$, et al. Patient preferences for outcomes of depression treatment in Germany: a choice-based conjoint analysis study. J Affect Disord. 2013;148(2-3):210-9.

32. Dwight-Johnson M, Lagomasino IT, Hay J, Zhang L, Tang L, Green JM, et al. Effectiveness of collaborative care in addressing depression treatment preferences among low-income Latinos. Psychiatr Serv (Washington, DC). 2010;61(11):1112-8.

33. Becker MP, Christensen BK, Cunningham CE, Furimsky I, Rimas H, Wilson F, et al. Preferences for early intervention mental health services: a discretechoice conjoint experiment. Psychiatr Serv (Washington, DC). 2016;67(2): 184-91.

34. Herman PM, Ingram M, Rimas H, Carvajal S, Cunningham CE. Patient preferences of a low-income Hispanic population for mental health services in primary care. Admin Pol Ment Health. 2016;43(5):740-9.

35. Flach SD, Diener A. Eliciting patients' preferences for cigarette and alcohol cessation: an application of conjoint analysis. Addict Behav. 2004;29(4):7919.

36. Cunningham CE, Henderson J, Niccols A, Dobbins M, Sword W, Chen Y, et al. Preferences for evidence-based practice dissemination in addiction agencies serving women: a discrete-choice conjoint experiment. Addiction. 2012;107(8):1512-24

37. Townend M. An application of conjoint analysis to the process of psychiatric day hospital care. J Psychiatr Ment Health Nurs. 2000;7(4):371-2.

38. Townend M, Shackley P. Establishing and quantifying the preferences of mental health service users for day hospital care: pilot study using conjoint analysis. J Ment Health. 2002;11(1):85-96.

39. Fahey A, Ní Chaoimh D, Mulkerrin EC, O'Keeffe ST, Mulkerrin GR. Deciding about nursing home care in dementia: A conjoint analysis of how older people balance competing goals. Geriatr Gerontol Int. 2017;17(12):2435-40.

40. Zipursky RB, Cunningham CE, Stewart B, Rimas H, Cole E, Vaz SM. Characterizing outcome preferences in patients with psychotic disorders: a discrete choice conjoint experiment. Schizophr Res. 2017;185:107-13.

41. Lee EJ, Chan F, Ditchman N, Feigon M. Factors influencing korean international students' preferences for mental health professionals: a conjoint analysis. Community Ment Health J. 2014:50(1):104-10.

42. Hajime S. Preferences for suicide prevention strategies among university students in Japan: a cross-sectional study using full-profile conjoint analysis. Psychol Health Med. 2018;23(9):1046-53.

43. Cunningham CE, Zipursky RB, Christensen BK, Bieling PJ, Madsen V, Rimas H, et al. Modeling the mental health service utilization decisions of university undergraduates: A discrete choice conjoint experiment. J Am College Health. 2017:65(6):389-99.

44. Okumura Y, Sakamoto S. Depression treatment preferences among Japanese undergraduates: using conjoint analysis. Int J Soc Psychiatry. 2012; 58(2):195-203.

45. Wymbs FA. Examining parents' preferences for varieties and elements of behavioral parenting programs: ProQuest Information \& Learning; 2012.

46. Wymbs FA. Parents' preferences for school- and community-based services for children at risk for ADHD. School Mental Health Multidiscipl Res Pract J. 2018:10(4):386-401.

47. Fegert JM, Slawik L, Wermelskirchen D, Nubling M, Muhlbacher A. Assessment of parents' preferences for the treatment of school-age children with ADHD: a discrete choice experiment. Expert Rev Pharmacoecon Outcomes Res. 2011;11(3):245-52.

48. Waschbusch DA, Cunningham CE, Pelham WE, Rimas HL, Greiner AR, Gnagy EM, et al. A discrete choice conjoint experiment to evaluate parent preferences for treatment of young, medication naive children with ADHD. J Clin Child Adolesc Psychol. 2011;40(4):546-61.

49. Cunningham CE, Chen Y, Deal K, Rimas H, McGrath P, Reid G, et al. The interim service preferences of parents waiting for children's mental health treatment: A discrete choice conjoint experiment. J Abnorm Child Psychol. 2013;41(6):865-77

50. Cunningham $C E$, Rimas $H$, Chen $Y$, Deal $K$, McGrath $P$, Lingley-Pottie $P$, et al. Modeling parenting programs as an interim service for families waiting for children's mental health treatment. J Clin Child Adolesc Psychol. 2015:44(4): 616-29.

51. Cunningham CE, Deal K, Rimas H, Buchanan DH, Gold M, Sdao-Jarvie K, et al. Modeling the information preferences of parents of children with mental 
health problems: a discrete choice conjoint experiment. J Abnorm Child Psychol. 2008;36(7):1123-38.

52. Riepe MW, Gritzmann P, Brieden A. Preferences of psychiatric practitioners for core symptoms of major depressive disorder: a hidden conjoint analysis. Int J Methods Psychiatr Res. 2017;26(1):e1528. https://doi.org/10.1002/mpr.1 528.

53. Ng-Mak D, Poon JL, Roberts L, Kleinman L, Revicki DA, Rajagopalan K. Patient preferences for important attributes of bipolar depression treatments: a discrete choice experiment. Patient Preference Adherence. 2018;12:35-44.

54. Bell RA, Paterniti DA, Azari R, Duberstein PR, Epstein RM, Rochlen AB, et al. Encouraging patients with depressive symptoms to seek care: a mixed methods approach to message development. Patient Educ Couns. 2010; 78(2):198-205

55. GBD 2017 Risk Factor Collaborators. Global, regional, and national comparative risk assessment of 84 behavioural, environmental and occupational, and metabolic risks or clusters of risks for 195 countries and territories, 1990-2017: a systematic analysis for the Global Burden of Disease Study 2017. Lancet. 2018;392(10159):1923-94. https://doi.org/10.1016/S01406736(18)32225-6 Epub 2018 Nov 8. Erratum in: Lancet. 2019 Jan 12; 393(10167):132. Erratum in: Lancet. 2019 Jun 22;393(10190):e44. PMID: 30496105: PMCID: PMC6227755.

56. Honda A, Ryan M, Van Niekerk R, Diane M. Improving the public health sector in South Africa: eliciting public preferences using a discrete choice experiment. Health Policy Plan. 2015;30(5):600-11. https://doi.org/10.1093/ heapol/czu038.

57. Lee S-J, Brooks R, Bolan RK, Flynn R. Assessing willingness to test for HIV among men who have sex with men using conjoint analysis, evidence for uptake of the FDA-approved at-home HIV test. AIDS Care. 2013;25(12):15928.

58. Huang MY, Huston SA, Perri M. Consumer preferences for the predictive genetic test for Alzheimer disease. J Genet Couns. 2014;23(2):172-8.

59. Herman PM, Ingram M, Cunningham CE, Rimas H, Murrieta L, Schachter K, et al. A Comparison of Methods for Capturing Patient Preferences for Delivery of Mental Health Services to Low-Income Hispanics Engaged in Primary Care. Patient. 2016;9(4):293-301.

60. Moor SE, Tusubira AK, Akiteng AR, Hsieh E. Development of a discrete choice experiment to understand patient preferences for diabetes and hypertension management in rural Uganda. Lancet Glob Health. 2020;8:S22. https://doi.org/10.1016/S2214-109X(20)30163-7.

61. Alguera-Lara V, Dowsey MM, Ride J, Kinder S, Castle D. Shared decision making in mental health: the importance for current clinical practice. Australas Psychiatry. 2017;25(6):578-82. https://doi.org/10.1177/103985621 7734711 Epub 2017 Oct 10. PMID: 29017332

62. Larson E, Vail D, Mbaruku G, Kimweri A, Freedman L, Kruk M. moving toward patient-centered care in Africa: a discrete choice experiment of preferences for delivery Care among 3,003 Tanzanian women; 2020.

63. Cunningham CE, Barwick M, Rimas H, Mielko S, Barac R. Modeling the decision of mental health providers to implement evidence-based children's mental health services: A discrete choice conjoint experiment. Adm Policy Ment Health Ment Health Serv Res. 2018;45(2):302-17.

64. Semrau M, Alem A, Ayuso-Mateos JL, Chisholm D, Gureje O, Hanlon C, et al. Strengthening mental health systems in low- and middle-income countries: recommendations from the Emerald programme. BJPsych Open. 2019;5(5): e73. https://doi.org/10.1192/bjo.2018.90.

65. Cunningham CE, Deal K, Rimas H, Chen Y, Buchanan DH, Sdao-Jarvie K. Providing information to parents of children with mental health problems: a discrete choice conjoint analysis of professional preferences. J Abnorm Child Psychol. 2009;37(8):1089-102.

\section{Publisher's Note}

Springer Nature remains neutral with regard to jurisdictional claims in published maps and institutional affiliations.

Ready to submit your research? Choose BMC and benefit from:

- fast, convenient online submission

- thorough peer review by experienced researchers in your field

- rapid publication on acceptance

- support for research data, including large and complex data types

- gold Open Access which fosters wider collaboration and increased citations

- maximum visibility for your research: over $100 \mathrm{M}$ website views per year

At BMC, research is always in progress.

Learn more biomedcentral.com/submissions 